\title{
Optimization of Ship Propulsion Diesel Engine to Fulfill the New Requirements for Exhaust Emissions
}

\section{Branko Lalića, Ivan Komara, Danilo Nikolićb}

\author{
KEY WORDS \\ $\sim$ Two-stroke low-speed marine diesel engines \\ $\sim$ Fuel injection \\ $\sim$ Combustion \\ $\sim$ Pollutant formation and composition \\ $\sim$ Reduction methods
}

\footnotetext{
a. University of Split, Faculty of Maritime Studies, Split, Croatia

e-mail: blalic@pfst.hr

e-mail: ivan.komar@pfst.hr
}

b. Faculty of Maritime Studies, Kotor, Montenegro

e-mail: fzpdekan@ac.me
Impacts of exhaust gas emissions on the environment and air pollution from ships have received considerable attention in the past few decades. Due to the characteristics of the combustion process, typical for large marine two-stroke low-speed engines, and the use of residual fossil fuels, the world's fleet emits into the atmosphere significant amount of pollutants such as nitrogen oxides $\left(\mathrm{NO}_{\mathrm{x}}\right)$, carbon monoxide $(\mathrm{CO})$, carbon dioxide $\left(\mathrm{CO}_{2}\right)$, hydrocarbons $(\mathrm{HC})$, sulphur oxides $\left(\mathrm{SO}_{\mathrm{x}}\right)$ and carbon particles (PM). Impact assessment of the process of their formation, emitted amounts and the influence of emission are important factors for decision making in regulation development and also for engine designers who aim to improve low-speed two-stroke marine engines, for further tightening of regulations regarding limiting emissions. This paper consists of three parts: the first section describes the injection and combustion process in lowspeed two-stroke marine engines, the second part describes the formation of the exhaust gas emissions as a product of the combustion process and the third part, in which the known techniques to reduce harmful emissions that are currently used in low-speed two-stroke marine engines are described. ${ }^{1}$ 


\section{INTRODUCTION}

Impact of exhaust gas emissions on the environment and air pollution from ships has received considerable attention in the past few decades. Due to the characteristics of the combustion process, typical for large marine two-stroke low-speed engines, and the use of residual fossil fuels, the world's fleet emits into the atmosphere a significant amount of pollutants such as nitrogen oxides $\left(\mathrm{NO}_{x}\right)$, carbon monoxide $(\mathrm{CO})$, carbon dioxide $\left(\mathrm{CO}_{2}\right)$, hydrocarbons $(\mathrm{HC})$, sulphur dioxide $\left(\mathrm{SO}_{2}\right)$ and carbon particles (PM). Knowing the process of their formation, emitted amounts and the influence of emission are important factors in improving the low-speed two-stroke marine engine and also for tightening of legislation limiting exhaust emissions.

\section{ENVIRONMENTAL LEGISLATION}

Constant increase in maritime traffic has caused the need to introduce legislation to limit emissions. Air pollution is mainly regulated by international and regional treaties which monitor the discharge of harmful substances into the atmosphere. Air pollution emissions from ships are particularly considered by the International Convention for the Prevention of Pollution from Ships, MARPOL 73/78 Convention. On 26 September 1997, at a meeting in London, Marine Environment Protection Committee (MEPC) adopted regulations in the form of a supplement to the MARPOL 1973/78 in the way that Annex VI of the Convention, which was then adopted, regulates discharge gases harmful to human health, such as nitrogen oxides $\left(\mathrm{NO}_{\mathrm{x}}\right)$, sulphur oxides $\left(\mathrm{SO}_{\mathrm{x}}\right)$, and various halogen gases CFCs that destroy the ozone layer from ships into the atmosphere. Annex $\mathrm{VI}$ entered into force on 19 May, 2005 when it was ratified by 25 member states of the IMO. On 10 October, 2008 Resolution MEPC.176 was adopted (58) "Amendments to Annex Protocol of 1997 amending the International Convention for the Prevention of Pollution from Ships", which entered into force on 1 July, 2010. The main changes are related to Regulation 13 on the progressive reduction of emissions of $\mathrm{NO}_{\mathrm{x}}$ and $\mathrm{SO}_{\mathrm{x}}$ in Regulation 14. An amendment to Annex $\mathrm{VI}$, in terms of emissions of $\mathrm{NO}_{x^{\prime}}$ is the introduction of two additional Tiers to existing restrictions which have been in force since 19 May 2005, as it is shown in Figure 1. Requirements for the control of emissions of $\mathrm{NO}_{x}$ are applied for each marine diesel engine with power greater than $130 \mathrm{~kW}$ installed on a ship and every marine diesel engine with power exceeding $130 \mathrm{~kW}$ -where significant modification was made on 1 January, 2000 or later, except to the satisfaction of the Maritime Administration to prove such an engine was an identical replacement for the engine to be replaced. These requirements do not apply to marine diesel engines intended for use only in emergency, or solely for the operation of any device or equipment intended for use only in emergency, or marine diesel engines installed in lifeboats intended for use only in emergency and the marine diesel engines installed on ships operating exclusively in waters under the sovereignty or jurisdiction of the State whose flag the ship flies.

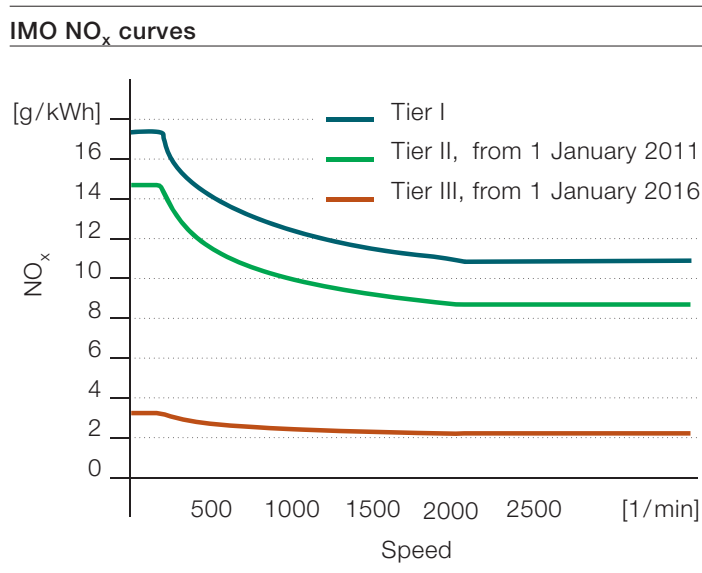

Figure 1.

MARPOL Annex VI, NOx emission limits (ABB Turbo Systems Ltd., 2010).

As the last activity of the IMO, in the field of environmental emission control from ships, we introduce the decision of the MEPC of the inclusion of the new Chapter 4 of MARPOL Annex $\mathrm{VI}$, referring to the "Rules for identification and control of energy efficiency" of ships EEDI, which came into force on 1 January 2013 and applies to all ships over 400 GT engaged in international navigation. The inclusion of Chapter 4 of Annex VI into MARPOL $73 / 78$ aims to improve the energy efficiency of ships by design and operational measures that would result in a reduction of $\mathrm{CO}_{2}$ emissions generated from fuel combustion process.

\section{COMBUSTION}

\subsection{Combustion Stoichiometry}

The aim of the combustion stoichiometry is to determine the required amount of air and fuel in order to achieve complete combustion. A stoichiometric mixture contains the exact amount of fuel and oxidizer, so that after combustion is completed, all the fuel and oxidizer are consumed to form products. This ideal mixture approximately yields the maximum flame temperature, as all the energy released from combustion is used to heat the products (McAllister et al., 2011). Combustion stoichiometry for a general hydrocarbon fuel, $\left(\mathrm{C}_{\alpha} \mathrm{H}_{\beta} \mathrm{O}_{y}\right)$ can be expressed by equation (1) and it is applied only for single-component HC. 


$$
\begin{aligned}
& \mathrm{C}_{\alpha} \mathrm{H}_{\beta} \mathrm{O}_{y}+\left(a+\frac{\beta}{4}-\frac{y}{2}\right) \cdot\left(\mathrm{O}_{2}+3.76 \mathrm{~N}_{2}\right) \rightarrow \\
& a \mathrm{CO}_{2}+\frac{\beta}{2} \mathrm{H}_{2} \mathrm{O}+3.76 \cdot\left(a+\frac{\beta}{4}-\frac{y}{2}\right)
\end{aligned}
$$

There are two typical approaches for multiple-component hydrocarbon fuels. The first method develops the stoichiometry of combustion using the general principle of atomic balance, making sure that the total number of $\mathrm{C}, \mathrm{H}, \mathrm{N}$ and $\mathrm{O}$ atoms is the same in the products and the reactants.

$$
\begin{aligned}
& 0.95 \mathrm{CH}_{4}+0.05 \mathrm{H}_{2}+1.925\left(\mathrm{O}_{2}+3.76 \mathrm{~N}_{2}\right) \rightarrow \\
& 0.95 \mathrm{CO}_{2}+1.95 \mathrm{H}_{2} \mathrm{O}+7.238 \mathrm{~N}_{2}
\end{aligned}
$$

The other method of balancing a fuel mixture is to first develop stoichiometry relations individually. Then, multiply the individual stoichiometry equations by the mole fractions of the fuel components and add them. For the study of the fossil fuel combustion it is necessary to know the fuel composition with the help of completed technical and elemental analysis of the fuel. Moisture, volatile combustible matter, solid combustible matter and ash are established by technical analysis. Elemental analysis of the fuel is provided by complex chemical methods such as carbon content in the fuel $\mathrm{c}\left[\mathrm{kg}_{\mathrm{c}} / \mathrm{kg}_{\mathrm{g}}\right]$, by weight of the carbon $\mathrm{C}\left[\mathrm{kg}_{\mathrm{c}}\right]$ per kilogram of fuel $\left[\mathrm{kg}_{\mathrm{g}}\right]$, hydrogen $h$, sulphur $s$, nitrogen $n$, oxygen $o$, ash and the moisture content $w$. From the very definition of the components that make the fuel, the following relation must be obeyed. Components involved in the process of fuel combustion that provide heat are carbon, hydrogen and sulphur.

$c+h+s+n+o+a+w=1$

The sulphur content in the fuel is very important because of the damaging effects of its compounds on the metal surfaces of the engine. The sulphur content is covered by only sulphur part, that exceeds the soot in the complete combustion, and not the part that remains tied up in ash. Oxygen helps combustion and the amount which is already contained in the fuel, has to be subtracted from the amount taken from the air. Nitrogen, ash and moisture are ballast in the combustion process. Ash can also contain a wide range of other elements such as $\mathrm{Br}, \mathrm{Ca}, \mathrm{Zn}, \mathrm{P}$, $\mathrm{V}$ and other elements. Since ash generally does not participate in the combustion process, from the thermal point of view we are not interested in its composition. However, the composition of ash may be important from the exploitation point of view because it is not irrelevant whether it remains solid or melts at high temperature (Bošnjaković, 1970). Each fuel component of the elemental analysis is considered separately via its own stoichiometric combustion equation. The combustion of $\mathrm{C}$ leads to its compound with $\mathrm{O}_{2}$ to form $\mathrm{CO}_{2}$ and energy is released, so the stoichiometric reaction equation is as follows:

$$
\mathrm{C}+\mathrm{O}_{2} \rightarrow \mathrm{CO}_{2}+33900 \mathrm{~kJ} / \mathrm{kg}_{\mathrm{c}} \rightarrow
$$

$1 \mathrm{kmol} C+1 \mathrm{kmolO} \mathrm{O}_{2} \quad 1 \mathrm{kmolCO}$

Moles of $\mathrm{C}_{1} \mathrm{O}_{2}$ and $\mathrm{CO}_{2}$ is calculated according to the equation (5)

$n=\frac{m}{M} \Rightarrow m=n \cdot M$

where $n$ - is mole of the species (kmol); $m$ - is mass of the species ( $\mathrm{kg}) ; M$ - is molar mass ( $\mathrm{kg} / \mathrm{kmol})$. Relative atomic weight of carbon $\operatorname{Ar}(\mathrm{C})$ is 12 and can be read from the periodic table and can be written as

$$
\begin{aligned}
M(C) & =\operatorname{Ar}(\mathrm{C})=12 \mathrm{~kg} / \mathrm{kmol} \\
M\left(\mathrm{O}_{2}\right) & =2 \cdot \operatorname{Ar}(\mathrm{O})=2 \cdot 16=32 \mathrm{~kg} / \mathrm{kmol} \\
M\left(\mathrm{CO}_{2}\right) & =\operatorname{Ar}(\mathrm{C})+2 \cdot \operatorname{Ar}(\mathrm{O}) \\
& =12+2 \cdot 16=44 \mathrm{~kg} / \mathrm{kmol}
\end{aligned}
$$

Substituting the obtained molar masses in the expression (5), we obtain the masses of participants, as follows:

$$
m(C)=n \cdot \operatorname{Ar}(C)=1 \mathrm{kmol} \cdot \frac{12 \mathrm{~kg}}{\mathrm{kmol}}=12 \mathrm{~kg}
$$

$$
\begin{aligned}
& m\left(\mathrm{O}_{2}\right)=n \cdot M\left(\mathrm{O}_{2}\right)=1 \mathrm{kmol} \cdot \frac{32 \mathrm{~kg}}{\mathrm{kmol}}=32 \mathrm{~kg} \\
& m\left(\mathrm{CO}_{2}\right)=n \cdot M\left(\mathrm{CO}_{2}\right)=1 \mathrm{kmol} \cdot \frac{44 \mathrm{~kg}}{\mathrm{kmol}}=44 \mathrm{~kg}
\end{aligned}
$$


Substituting the obtained masses of the species in the expression (4) and rearranging the equation

$\mathrm{ckgC}+2.67 \mathrm{ckgO}_{2} \longrightarrow 3.67 \mathrm{ckgCO}$

Similar to the previous procedure, during the combustion of hydrogen and sulphur, the stoichiometric reaction equations are as follows:

$$
\begin{aligned}
& h \mathrm{kgH}_{2}+8 \mathrm{hkgO}_{2} \longrightarrow 9 \mathrm{hkgH}_{2} \mathrm{O} \\
& \mathrm{skgS}+\mathrm{skgO}_{2} \longrightarrow 2 \mathrm{skgSO}_{2}
\end{aligned}
$$

The required amount of oxygen for combustion will be: for $\mathrm{c}$ $\mathrm{kg}$ carbon 2,67c kg, for h kg hydrogen $8 \mathrm{~h} \mathrm{~kg}$, for $\mathrm{s} \mathrm{kg}$ sulphur s kg. Stoichiometric amount of oxygen required for the combustion of $1 \mathrm{~kg}$ of fuel is:

$O_{\min }=2.67 \cdot \mathrm{c}+8 \cdot \mathrm{h}+\mathrm{s}-\mathrm{o} \frac{\mathrm{kg} \mathrm{o}_{2}}{\mathrm{~kg}}$

or expressed in volume units

$$
\begin{aligned}
O_{\min }= & 1.867 \cdot \mathrm{c}+5.603 \cdot h+0.700 \cdot \mathrm{s} \\
& -0.700 \cdot 0 \frac{\mathrm{m}_{n}^{3} \mathrm{O}_{2}}{\mathrm{~kg}_{f}}
\end{aligned}
$$

For the combustion process in diesel engine, oxygen from the air is used. The amount of $\mathrm{O}_{2}$ in air is $23.3 \%$ by mass or $21 \%$ by volume; the minimum required amount of $\mathrm{O} 2$ for theoretical combustion is:

$$
A_{o}=\frac{2,67 \cdot c+8 \cdot h+s+o}{0,232} \frac{\mathrm{kg}_{a}}{\mathrm{~kg}_{f}}
$$

$$
A_{o}=\frac{1.867 \cdot c+5.603 \cdot h+0.700 \cdot s-0.7000}{0.232} \frac{m_{n a}^{3}}{k g_{f}}
$$

\subsection{Diesel engine combustion}

In order for ignition and combustion to occur, fuel must first be mixed with an oxidizing agent. Ignition and combustion are chemical processes, and they are necessarily observed through chemical kinetics for better understanding. According to kinetic theory, gases consist of molecules which move chaotically at medium speed in a certain area under specific environmental condition. If the gas temperature increases, the kinetic energy of the molecules will increase. If the molecules of the fuel and oxidizer are mixed so that there are no differences in local concentrations, then the mixture is considered to be homogeneous. Their mutual reaction, with respect to ignition, will appear only when there is a collision between their individual molecules. Collision energy must be such as to destroy all the internal links in the molecule, which happens only when the activation energy $E$ limit is exceeded. The number of effective collisions can be expressed by equation (13), and the value of effective collision is between 0 and $1(0<A<1)$

$A=e^{-\frac{E}{R \cdot T}}$

where $A$ - number of effective collisions, $E$ - activation energy, $\mathrm{kJ} / \mathrm{mol}, R$ - gas constant, $\mathrm{J} / \mathrm{molK}, T$ - reaction temperature, $K$. The equation shows that the proportion of effective collision depends on the temperature, but the number of effective collisions also depends on the concentration of the reactants. Ignition and combustion of fuel depend on the composition of the fuel mixture, i.e. about the participation of fuel in the mixture, so the mixture can be stoichiometric, rich or lean.

\subsubsection{Combustion flow}

Process of combustion of fuel is comprised of the following steps: entry of fuel jet into the combustion chamber; disintegration of the jet into droplets; decomposition of larger droplets into smaller; droplets heating; droplets evaporation; mixing of fuel vapour with the surrounding air; simultaneous auto ignition of fuel mixture in several places; continued evaporation of the droplets and burning around (diffusion combustion); formation of soot during combustion in an area near droplets; temperature drop and slowing reaction due to expansion in the cylinder. While the combustion temperature is still high, it is necessary that the particular matters find their reactants (oxygen) to complete combustion reaction. The phases until the simultaneous ignition of fuel mixture in several places represent a delayed auto-ignition. Delayed ignition can be defined as the time or crank angle that elapses from the beginning of 
fuel ignition to the auto-ignition of the mixture. Analysing and improving the above phases, determinants of optimal processes with less pollutant in exhaust gas emissions and with better fuel efficiency are obtained.

\subsubsection{Fuel jet formation}

A good spatial distribution of fuel affects the proper, soft and economical operation of the engine. To achieve a good spatial distribution of fuel, it must be injected at a rate of about $250 \mathrm{~ms}^{-1}$, which requires a pressure of over $80 \mathrm{MPa}$. Dispersion quality is determined by the injection speed, fuel surface tension, fuel viscosity, density of air in the cylinder, turbulence and cavitation in the nozzle. Opening angle, direction and size of the nozzle hole is determined by the depth of penetration, and the angle of propagation of the jet. Better turbulence, mixing with air and combustion can be achieved by better penetration and propagation of jet fuel. With two-stroke low-speed diesel engine injection is usually done by three injectors with the nozzles that direct the fuel tangentially into the cylinder space. Under the influence of aerodynamic forces of compressed air, fuel jet expands and disintegrates into small droplets. The quality of the fuel spray is defined by average diameter of most droplets and droplet sameness. Better fuel dispersion is achieved with the smaller nozzle holes' diameters and a larger number of holes, greater injection pressure and higher compression pressure inside the cylinder. Fuel speed discharge from the short duct nozzle is approximately calculated according to equation

$v_{f}=\Phi_{f} \cdot \sqrt{\frac{2 \cdot\left(p_{i}-p_{c}\right)}{\Phi_{f}}} m s^{-1}$

where: $v_{f}$ - fuel speed discharge, $m s^{-1} ; p_{i}$ - injection pressure, $P a$; $P_{c}$ - compression pressure, $P_{d^{\prime}} \varphi_{f}$ - fuel density, $\mathrm{kgm}^{-3} ; \Phi_{f}$ - fuel discharge coefficient. The minimal injection pressure is presented by equation

$p_{i}=p_{c}+\frac{v_{f}^{2} \cdot \varphi_{f}}{2 \cdot \Phi_{f}^{2}} P a$

At the beginning of the fuel injection the speed is maximal, and therefore the resistance to the movement of fuel in compressed air is the biggest. In this period the jet speed reduction is the most pronounced. The shape of the fuel jet is affected by injection pressure, pressure and temperature in the area of injection, fuel jet swirl as it passes through the injector nozzle holes and injection construction. Acuteness of jet increases with increasing of injection pressure and holes diameter opening on the injector nozzle. Airflow inside the cylinder has a significant impact on fuel jet formation. In the case of intensive air flow inhomogeneity of the jet in terms of droplet size, provides a better opportunity to achieve a good mixture. The efficiency of air indicates the quality of mixture formation, i.e. how long it is homogeneous throughout the combustion chamber. Sauter (Volmajer and Kegl, 2003) defined droplet size according to the volume of the combustion chamber. The reference diameter of the droplets $\left(d_{32}\right)$ is used to describe the fineness of the spray. It is the ratio between the sum of the volumes of the droplets and the sum of the surface of the droplets, and it is defined as

$d_{32}=\frac{\sum_{i} N_{i} \cdot d_{i}^{3}}{\sum_{i} N_{i} \cdot d_{i}^{2}}$

where: $N$ - is the number of droplets, $d^{2}$ - droplet surface, $\mathrm{mm}^{2}$, $d^{3}$ - droplet volume, $\mathrm{mm}^{3}$, and is commonly used for defining of atomization of the fuel spray. For good combustion it is more important to evenly distribute the fuel in the air, even in the form of larger particles, than to achieve local mixtures which, due to poor penetration of droplets, are not sufficiently mixed with air. With the temperature increase of fuel, the spray is better, the width of the jet increases and the length decreases.

\subsubsection{Fuel jet breakup}

Fuel injection is usually displayed by ratio of fuel injected $(\mathrm{dm})$ per unit angle $(\mathrm{d} \varphi)$ as a function of the crankshaft angle $(\varphi)$. Once the fuel is injected into the combustion chamber, due to the high injection pressure the jet it disintegrates into droplets and creates turbulent eddies in the fuel jet and their collision with compressed air. Preferably, fuel jet breaks up into a large number of small droplets as it increases the surface area in relation to the mass of fuel injected. A fuel droplet at its partial pressure is subjected to a pressure that first deformed it until fully halved, and that process can be repeated for several times. The injected fuel, which has great turbulence, has a shorter range and better dispersion. Improvement of fuel mixture formation is greatly affected by the flow of air into the cylinder, and it is deliberately 
increased by the angle of cylinder liner scavenging openings. If an excessively turbulent flow of air is created, it can lead to burning fuel droplets contact with the cold cylinder liner wall and its extinction. Fuel discharge from the nozzle hole leads to its disintegration, and he can be a primary or secondary breakup. In the primary dissolution fuel jet is divided into vertical volumes and droplets at the outlet of the nozzle, while the secondary breakup is described as the further disintegration of the droplet, under the action of the compressed air to the formation of a stable droplet diameter.

During the breakup of fuel jet from the cylindrical holes into the combustion space, several different areas of the breakup are known (Ofner, 2001):

- The Rayleigh breakup and induced air stream breakup are achieved at very low Reynolds numbers and low-pressure injection. The breakup takes place during the injector needle closing or immediately after the opening of the needle.

- $\quad$ First breakup by induced current generated is increased by output speed. Increasing the relative speed of the jet in the combustion chamber, the influence of aerodynamic effects grows, and higher air density enhances the effect.

- Secondary breakup by induced current occurs at Reynolds number greater than 2,300 .

- The atomization is technically the most important mechanism of droplet breakup. The breakup occurs at high Reynolds number and high output speed from the nozzle, and the breakup begins immediately after droplet exits the nozzle hole.

An action of aerodynamic forces that cause secondary breakup is added to the primary breakup of the droplets. Figure 2 represents four types of secondary breakup (Ofner, 2001; Krugler, 2001).

- $\quad$ For small Weber numbers of about 12, vibrational breakup occurs due to droplet vibration until at some point it breaks up into two droplets of similar sizes.

- $\quad$ Bag breakup $(12<\mathrm{We}<50)$ oscillation of the fuel droplets enhances the flow of the environment, and the droplets' breakup is carried out by membranes' bursting.

- Bag/streamer breakup $(50<\mathrm{We}<100)$, decomposition of the core is similar to the breakdown of the bubble. The form of a droplet transforms into the form of a disc perpendicular to the direction of flow, and then the centre of the disk takes the form of a parachute. Thereafter, the centre of the parachute breaks up into small droplets and the parachute cone disintegrates into bigger droplets.

- $\quad$ Stripping breakup $(100<\mathrm{We}<350)$, a large number of small droplets are stripped away from the surface of the droplet periphery, due to aerodynamic forces on the drop surface.

- $\quad$ Catastrophic breakup $(350<<\mathrm{We})$, after forming, diskshaped droplets decay throughout the volume in a cascade form into very small pieces.

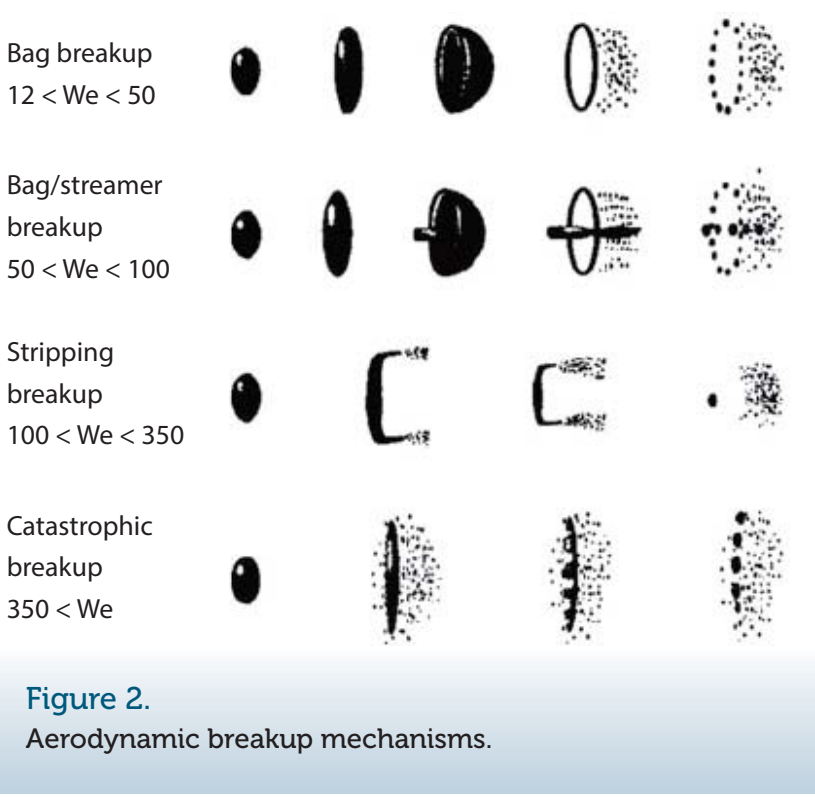

Once the fuel is broken up into droplets, heating, evaporation and combustion of droplets follow.

\subsubsection{Combustion process}

The combustion process in a diesel engine can be divided into four phases, which are shown in the diagram in Figure 3. The first phase, „Ignition delay, curve C-E", defines the period from the beginning of injection until the ignition starts, and has an impacton the pollutant formation (Golovichev and Nordin, 2001; Ishiyama, et al., 2001). This period defines fuel atomization, evaporation, mixing and the reaction start. At sufficiently low turbulence local flame fronts are created, which eventually increase to the overall flame. Turbulent flames of homogeneous mixture produce high temperature without soot (Urlaub, 1995). The second phase, "Uncontrolled combustion, curve E-F", is a homogeneous phase of combustion. It is determined from the beginning of combustion until a significant drop rate of combustion. At this stage, there are sudden ignition and combustion of the already prepared fuel mixture during the delayed ignition phase. Combustion begins simultaneously in several places and conducts intensively, and there is a sudden increase in the pressure and the temperature. The third phase, "Partially controlled combustion, curve F-G", is diffusion combustion in which fuel droplets vaporize from the surface. Evaporated fuel is mixed with air, and combustion speed is limited by the rate of fuel evaporation and the speed of creating fuel mixture. 


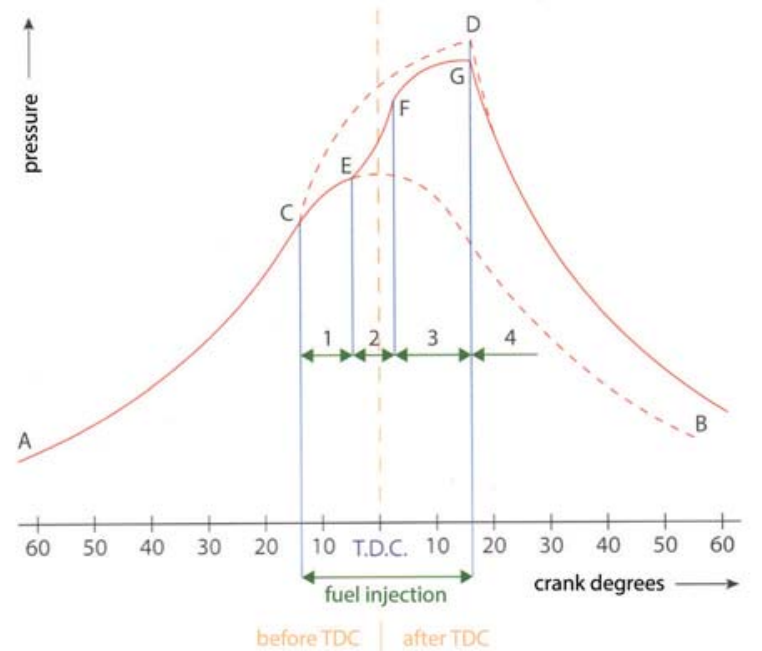

Figure 3.

Phases of the combustion process (Kuiken, 2012).

He fourth phase, "After burning, curve G-till end", is the final part of the combustion and it takes about half of the total duration of combustion. Reactions slow down due to expansion and smaller amounts of reactants. A part of soot that is created during combustion leaves the cylinder as part of emissions.

\subsubsection{Adiabatic flame temperature}

One of the most important features of a combustion process is the highest temperature of the combustion products that can be achieved. The temperature of the products will be the highest when there are no heat losses to the surrounding environment and all of the energy released from combustion is used to heat the products. An adiabatic constant-pressure analysis is used here to calculate the adiabatic flame temperature $T_{\text {ATP. }}$. Three different methods can be used to obtain $T_{\text {ATP: }}$ :

- Using a mean specific heat capacity $\bar{c}_{p}$,

- An iterative enthalpy balance,

- $\quad$ Finding the equilibrium state using computer software.

- Using an average $\bar{c}_{p}$ value method the adiabatic flame temperature is calculated for a lean mixture $\Phi \leq 1$, as follows:

$$
T_{\text {ATP }}=T_{R}+\frac{\Phi \cdot f_{s} \cdot L H V}{\left(1+\Phi \cdot f_{s}\right) \cdot \bar{C}_{p, P}}
$$

where: $T_{R}$ - represents the temperature of the reactants, i.e. fuel which after injection and ignition delay has the compression temperature $\left(T_{2}\right)$

$T_{2}=T_{1} \cdot \varepsilon^{n-1}$

where: $T_{2}$ represents temperature at the end of compression; $T_{1}$ - temperature at the beginning of compression; $\varepsilon$ - the compression ratio; $n$ - polytrophic exponent. Since the volumes of the engine at the beginning and at the end of compression are known and pressures are measurable, exponent polytrophic is (Bošnjaković, 1970)

$n=\frac{\log P_{1}-\log P_{2}}{\log V_{2}-\log V_{1}}$

$\Phi$ represents equivalence ratio for lean mixture; $f_{s}$ - is the stoichiometric fuel air ratio; $L H V$ - is lower heating value of fuel; $\bar{c}_{p, P}$ - is an average value of specific heat of the products.

An iterative enthalpy balances method, despite its being a more accurate approach, requires the complete combustion of the reactants into main products, and cannot be applied to diesel engines.

\section{EXHAUST EMISSION}

The main pollutants in exhaust emissions occur as a direct result of the combustion process in the engine cylinder. The quality of used fuel has an important role in determining the content of emissions, and the engine speed is shown as one of the main factors that determine the amount of $\mathrm{NO}_{\mathrm{x}}$ in the exhaust emissions. The other major pollutants from combustion are $\mathrm{CO}$, unburned $\mathrm{HC}$, soot, $\mathrm{SO}_{x^{\prime}}$ and oxides of metals.

\subsection{Nitrogen oxides ( $\left.\mathrm{NO}_{\mathrm{x}}\right)$}

$\mathrm{NO}_{x}$ consist of $\mathrm{NO}$ and $\mathrm{NO}_{2}$. $\mathrm{NO}$ is represented by approximately $90 \%$ of the volume, $\mathrm{NO}_{2}$ by about $5 \%$ of the volume, while nitrogen (I) oxide, nitrogen trioxide and nitrogen pentoxide occur in traces. $\mathrm{NO}_{\mathrm{x}}$ are strongly dependent on the temperature of combustion, the local $\mathrm{O}_{2}$ concentration and duration of the combustion process. Injection time, turbocharged air temperature, fuel quality as well as mixture quality have an impact on combustion and should be mentioned. Research suggests that $\mathrm{NO}_{\mathrm{x}}$ are mainly formed during the diffusion combustion period, but occurs to a lesser extent during the homogeneous phase. 


\subsubsection{Thermal NO}

Three major steps are responsible for thermal NO formation. The first two form the basis of the Zeldovich mechanism (McAllister et al., 2011; Zeldovich, 1946; Lavoie et al., 1970).

$$
\begin{aligned}
\mathrm{N}_{2}+\mathrm{O}_{2} \stackrel{k_{1}}{\longrightarrow} \mathrm{NO}+\mathrm{N} \\
k_{1}=1.8 \cdot 10^{14} \cdot \mathrm{e}^{\left(\frac{-38370}{T}\right)} \\
\mathrm{N}+\mathrm{O}_{2} \stackrel{k_{2}}{\longrightarrow} \mathrm{NO}+\mathrm{O} \\
\mathrm{k}+\mathrm{OH} \stackrel{k_{3}}{\longrightarrow} \mathrm{NO}+\mathrm{H} \cdot 10^{10} \cdot \mathrm{T} \cdot \mathrm{e}^{\left(\frac{-4680}{T}\right)} \\
\mathrm{k}=7.1 \cdot 10^{13} \cdot \mathrm{e}^{\left(\frac{-450}{T}\right)}
\end{aligned}
$$

In terms of combustion in a diesel engine, expanded Zeldovich reaction mechanism is kinetic, which means that under the conditions during combustion in a diesel engine chemical equilibrium concentration of nitrogen oxides won't be achieved. The first two reactions correspond to the formation of $\mathrm{NO}$ in the lean mixture and the last one in the formation of a rich mixture. The first reaction is determined by the reaction rate due to its high activation temperature of about $38,000 \mathrm{~K}$. The high activation energy was required to break the triple bond in the molecule of nitrogen that occurs at high temperatures, and hence the name of the Thermal nitrogen monoxide. From the equations (20), (21) and (22), the expression for the rate of formation of $\mathrm{NO}$ is as follows

$$
\frac{d[\mathrm{NO}]}{d t} \cong k_{1}\left[\mathrm{~N}_{2}\right][\mathrm{O}]+k_{2}[\mathrm{~N}]\left[\mathrm{O}_{2}\right] \cong 2 k_{1}\left[\mathrm{~N}_{2}\right][\mathrm{O}]
$$$$
\cong 1.476 \cdot 10^{15}\left[\mathrm{~N}_{2}\right]\left[\mathrm{O}_{2}\right]^{\frac{1}{2}} \cdot e^{\left(-\frac{67520}{T}\right)} \mathrm{mol} \mathrm{cm} \mathrm{cm}^{-3}
$$

where: $\mathrm{NO}$ - is the concentration of molecules of nitric oxide, $\mathrm{N}_{2}$ - is the concentration of nitrogen molecules, $\mathrm{O}$ - is the concentration of oxygen atoms. From this we can conclude that the reduction of NO can be achieved by the reduction of reaction rate constant, i.e. lowering the combustion temperature and reducing the concentration of $\mathrm{O}_{2}$ and $\mathrm{N}$ as well. $\mathrm{NO}$ formation is often denoted in [ppms-1], and the equation for mole fractions of the observed species is:

$$
\frac{d n_{\mathrm{NO}}}{d t} \cong 1.476 \cdot 10^{21} \cdot n_{\mathrm{N}_{2}}^{\frac{1}{2}} \cdot n_{\mathrm{O}_{2}} \cdot e^{\left(-\frac{67520}{T}\right)} \cdot\left(\frac{P}{R \cdot T}\right)^{\frac{1}{2}} \mathrm{ppm}^{-1}
$$

According to Bowman the expression for the total rate of nitrogen oxides formation is [27]

$$
\frac{d n_{N O}}{d t} \cong 1.476 \cdot 10^{21} \cdot n_{N_{2}}^{\frac{1}{2}} \cdot n_{O_{2}} \cdot e^{\left(-\frac{67520}{T}\right)} \cdot\left(\frac{P}{R \cdot T}\right)^{\frac{1}{2}} \mathrm{~mol} \mathrm{~cm}^{-3} \mathrm{~s}^{-1}
$$

\subsubsection{Prompt NO formation}

NO can be produced promptly at the flame front by the presence of hydrocarbon radicals, an intermediate species produced only at the flame front at relatively low temperature. NO generated via this route is named "prompt NO" as proposed by Fenimore. $\mathrm{HC}$ radicals react with $\mathrm{N}$ molecules with the following sequence of reaction steps:

$$
\mathrm{CH}+\mathrm{N}_{2} \longrightarrow \mathrm{HCN}+\mathrm{N}
$$

$\mathrm{HCN}+\mathrm{N} \longrightarrow \ldots \rightarrow \mathrm{NO}$ 
$\mathrm{N}$ atoms generated from (26) can react with $\mathrm{O}_{2}$ to produce NO. Nitrogen reacts with a $\mathrm{HC}$ radical to produce hydrogen cyanide $(\mathrm{HCN})$, and further $\mathrm{HCN}$ reacts with $\mathrm{N}$ to produce $\mathrm{NO}$ via a series of intermediate steps. The activation temperature of (26) is about $9,020 \mathrm{~K}$. In contrast to thermal mechanisms that have an activation temperature about 38,000 K from (27), prompt NO can be produced starting at low temperatures around 1,000 K.

\subsection{4 $\mathrm{N}_{2} \mathrm{O}$ Route}

Under high pressures, the following three-body recombination reaction can be produced through:

$$
\mathrm{N}_{2}+\mathrm{O}+\mathrm{M} \longrightarrow \mathrm{N}_{2} \mathrm{O}+\mathrm{M}
$$

Due to the nature of three-body reactions, ( $M$ represents inert molecule, and it could be any) the importance of (28) reaction increases with pressures. As soon as $\mathrm{N}_{2} \mathrm{O}$ is formed, it reacts with oxygen $\mathrm{O}$ to form $\mathrm{NO}$ as follows:

$\mathrm{N}_{2} \mathrm{O}+\mathrm{O} \longrightarrow \mathrm{NO}+\mathrm{NO}$

Reaction (29) has an activation temperature around 11,670 $\mathrm{K}$ and therefore $\mathrm{NO}$ can be formed at low temperatures of around $1,200 \mathrm{~K}$.

\subsubsection{Fuel-Bound Nitrogen FBN}

FBN, mostly from solid fuels, is produced by oxidation of nitrogen that is chemically bound in the fuel molecule. If this fuel molecule comes at the flame front, it turns into radicals, respectively into cyanide compounds, which at the flame front area partly oxidize to NO.

\subsection{Soot formation}

The soot emission is generated by combustion in a diesel engine and mainly consists of unburned fuel and lubricating oil, and their size ranges from $20 \mathrm{~nm}$ up to 10 microns. Particulate emission is separated into a soluble organic fraction SOF and an insoluble or dry fraction IF, which is often used as an estimation of soot. The percentage of particles and soot in the total emission is about 40-50 \%. Other PM constituents are water, wear metals, ash from burned fuel and lubricant oil and fuel-derived sulphate. The sulphuric acid/sulphate fraction is roughly proportional to the fuel $\mathrm{S}$ content. The fraction associated with unburned fuel and lube oil varies with engine design and operating condition and it can range from less than $10 \%$ to more than $90 \%$ by mass (Rakopoulos and Giakoumis, 2009). According to the acetylene hypothesis, soot is formed from unburned fuel that nucleates from the vapour phase to a solid phase in fuel-rich regions at elevated temperatures. $\mathrm{HC}$ or other available molecules may condense on, or be absorbed by soot, depending on the surrounding conditions. The evolution of liquid- or vapour-phase $\mathrm{HC}$ to solid soot particles, and possibly back to gas-phase products, involves six commonly identified processes: pyrolysis, nucleation, surface growth, agglomeration and oxidation. Conversion of more than $50 \%$ of soot is achieved at 1,500 K. Maximum 80 to $90 \%$ of soot can be oxidized at the peak temperature of $1,700 \mathrm{~K}$. With a further increase in temperature higher oxidation is not achieved, which can be explained by the effect of extinction in the near cold cylinder wall. The temperature of $1,300 \mathrm{~K}$ is called the boundarytemperature decomposition of soot. Furthermore, by exceeding this limit temperature there is specific time after which soot begins to dissolve, and which is defined as the time reduction.

\section{TECHNIQUES FOR REDUCING EXHAUST EMISSIONS}

Emissions of $\mathrm{NO}_{x}$ can be reduced by primary and secondary methods, or a combination of both methods. The primary methods are called all engine design changes, while secondary methods are all methods of exhaust gas treatment. The most important primary methods are: Performance adjustment; Scavenge Air Moistening SAM; Water-in-Fuel emulsion WIF; Exhaust Gas Recirculation EGR.

While the most important secondary methods are: Selective Catalytic Reduction SCR.

\subsection{The primary methods}

\subsubsection{Performance adjustment}

The concept of reducing the concentration of NOx and soot due to the optimization of the engine entails a change in one or more engine parameters such as fuel injectors and the shape of its nozzle, the start of fuel injection, fuel injection pattern, opening of the exhaust valve, fuel injection pressure, compression ratio and scavenging air pressure and temperature.

\section{Fuel injectors and nozzle form}

Two-stroke low-speed marine engines have two or three fuel injectors that are on the edge of the combustion chamber. The interaction between the fuel jets from the holes of the nozzle has a significant impact on the amount of $\mathrm{NO}_{x}$ formation, thus there is an optimum number of holes on each fuel injector nozzle (Goldsworthy, 2002). In a small number of holes in the nozzle delayed interaction of high combustion temperatures and air in the zones between the fuel jets leads to an increase in the 
temperature, which ultimately leads to a $50 \%$ decrease in the content of $\mathrm{NO}_{x}$ in the exhaust gas emissions.

\subsubsection{Water-in-Fuel emulsion WIF}

When using WIF techniques, water is continuously added to the fuel during its consumption, and the homogeneity of the emulsion is ensured mechanically in a homogenizer. When the emulsion is injected into the engine, it comes to the seizure of heat of combustion due to heating, evaporation and superheating of water. That leads to lower peak temperature and better fuel atomization, which results in approximately $1 \%$ reduction in the content of $\mathrm{NO}_{\mathrm{x}}$ for every $1 \%$ of added water. To achieve the optimum fuel atomization, the droplet size must be a maximum of $5 \mu \mathrm{m}$, which can be achieved in an ultrasonic homogenizer. In order to maintain the set viscosity values of 12 to $15 \mathrm{~mm} 2 / \mathrm{s}$, it is necessary to raise the emulsion temperature to about $150^{\circ} \mathrm{C}$, and even more if the water content increases (Unknown, 2009; Lalić et al., 2009).

\subsubsection{Cylinder liner lubrication}

The research done by MAN B \& W Diesel A / S suggests that the reduction of cylinder oil consumption reduces particulates and soot emissions. Due to environmental and engine operative needs, electronically controlled high-pressure cylinder oil injection system for lubrication at a predetermined time and piston position that ensures optimal lubrication in all the engine operational regime has been developed. Today Alpha Adaptive Cylinder Oil Control ACC from MAN Diesel Company or Pulse
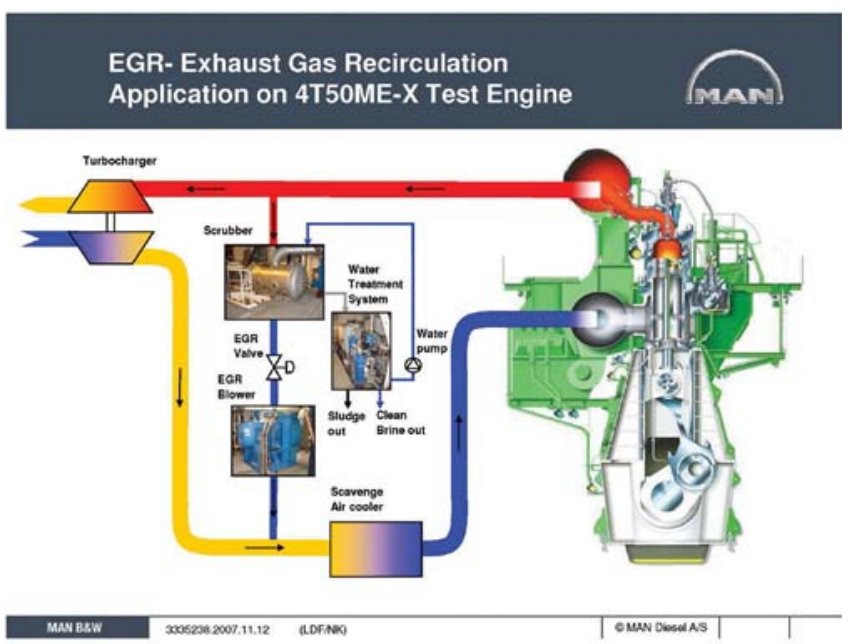

Figure 4

EGR system
Lubricating System from Wärtsilä Sulzer Company represents standard systems used for cylinder liner lubrication.

\subsubsection{Exhaust Gas Recirculation EGR}

EGR recirculation system implies only a portion of exhaust emission recirculation, Figure 4. After removal of soot and $\mathrm{SO}_{\mathrm{x}^{\prime}}$ the part of the exhaust gases mix with the scavenging air before entering the cooler and the presence of $\mathrm{CO}_{2}$ and $\mathrm{H}_{2} \mathrm{O}$ increases the heat capacity of the resulting mixture. Furthermore, the $\mathrm{O}_{2}$ concentration is reduced, which means that the engine must be charged with a larger amount of the purified exhaust gas and fresh turbocharged air mixture for a complete combustion of the same amount of fuel. Due to the increase of heat capacity and scavenging mixture mass, a reduction of peak combustion temperature occurs and, thus, lower concentration of $\mathrm{NO}_{x}$. From all the above mentioned methods EGR system has the best predisposition in terms of meeting the new requirements on the content of $\mathrm{NO}_{\mathrm{x}}$ to fulfil Tier III requirements.

\section{CONCLUSION}

In the past few decades shipping industry and maritime transport have been developing rapidly. From the economic point of view, this trend has a positive impact on economic development but, on the other hand, a very negative impact on the environment in terms of air pollution. When considering air pollution from ships, it primarily refers to emissions such as $\mathrm{NO}_{\mathrm{x}^{\prime}}$ $\mathrm{SO}_{x^{\prime}} \mathrm{PM}$ and soot, which are the products of fossil fuel combustion in marine diesel engines. Therefore, today all major manufacturers of two-stroke low-speed marine diesel engines produce engines that meet the requirements of MARPOL Convention 1973/78, Annex Vl. This paper presents the effect of temperature on the formation of pollutants in the exhaust emission. With the aim to reduce these pollutants in the exhaust gas emissions from marine engines, a variety of methods have been proposed and implemented and they are presented in this paper. Satisfaction of these regulations is achieved by the described primary and secondary methods. The rate of formation of concentration of thermal $\mathrm{NO}$ as the biggest factor in $\mathrm{NO}_{x}$ emissions and the impact of flame temperature on increasing the speed of its concentration are specially emphasized in this paper. Both in the present and in the future, further development of engine parameter optimization in order to improve its performance and meet increasingly stricter environmental standards remain an imperative. 


\section{REFERENCES}

ABB Turbo Systems Ltd., (2010), The Power2 miracle - NOx down, power up, fuel down, ABB Turbocharging, Baden: ABB Turbo Systems Ltd.

Bošnjaković, F., (1970), Nauka o toplini 1. dio, (in Croatian), Zagreb: Tehnička knjiga.

Bowman, C. T., (1975), Kinetics of Pollutant Formation and Destruction on Combustion, Progress in Energy and Combustion Science, 1(1), pp. 33-45., http://dx.doi.org/10.1016/0360-1285(75)90005-2

Brown, D. and Holtbecker, R., (2007), Next steps in exhaust emissions control for Wärtsilä low-speed engines, Wärtsilä Technical Journal, 1, pp. 34-37.

Goldsworthy, L., (2002), Design of ship engines for reduced emissions of oxides of nitrogen, Faculty of Maritime Transport and Engineering, Australian Maritime College, available at: http://www.flamemarine.com/files/AMCPaper.pdf

Golovichev, V. I. and Nordin, N., (2001), Detailed Chemistry Spray Combustion Model for the Kiva Code, User's Group Meeting at the SAE Congres, Detroit, MI, March 4., available at: https://www.erc.wisc.edu/documents/ Chalmers.pdf

Holtbecker, R. and Geist, M., (1998), Emissions Technology, Sulzer RTA Series, Exhaust Emissions Reduction Technology for Sulzer Marine Diesel Engines, Wartsila NSD.

Ishiyama, T., Shioji, M. and Ihara, T., (2001), Prediction of Ignition Processes in Fuel Sprays Includings Turbulent Mixing and Reduced Chemical Reaction Models, COMODIA 2001, Nagoya, Japan, July 1-4, pp. 77-84.

Krugler, C., (2001), Validierung eines 1D-Spraymodells zur Simulation der Gemischbildung in direkteinspritzenden Dieselmotoren, Disertaion, Achen: Technischen Hochschule Achen.

Kuiken, K., (2012), Diesel Engines, Part I, Onnen: Target Global Energy Training.
Lalić, B., Komar, I., Kulenović, Z. and Antonić, R., (2009), Water-in- fuel emulsion as a primary method to remove NOx from diesel engine exhaust gas, 13th International Research / Expert Conference TMT 2009, Hammamet, Tunisia, October 16-21, pp. 457-460., available at: http://www.tmt.unze.ba/zbornik/TMT2009/115-TMT09-067. pdf

Lavoie, G. A., Heywood, J. B. and Keck, J. C., (1970), Experimental and Theoretical Investigation of Nitric Oxide Formation in Internal Combustion Engines, Combustion Science Technology, 1, pp. 313-326.

McAllister, S., Chen, J. Y. and Fernandez-Pello, A. C., (2011), Fundamentals of Combustion Processes, Springer Science+Business Media.

Ofner, B., (2001), Dieselmotorische Kraftstoffzerstäubung und Gemischbildung mit Common-Rail Einspritzsystemen, PhD Thesis, München: Technischen Unversität München.

Rakopoulos, C. D. and Giakoumis, E. G., (2009), Diesel Engine Transient Operation - Principles of Operation and Simulation Analysis, London: Springer-Verlag Ltd., http://dx.doi.org/10.1007/978-1-84882-375-4

Urlaub, A., (1995), Verbrennungsmotoren (Grundlagen, Verfahrenstheorie, Konstruktion), Berlin: Springer-Verlag.

Unknown, (2009), Emission Control Two-Stroke Low-Speed Diesel Engines, MAN B\&W Diesel A/S, Copenhagen, Denmark, available at: http://www.flamemarine. com/files/MANBW.pdf

Volmajer, M. and Kegl, B., (2003), Biodizel i otpadno jestivo ulje kao alternativna goriva: analiza s aspekta procesa ubrizgavanja, (in Croatian), Goriva i maziva, 42 (3), pp. 177-197.

Zeldovich, Y. A., (1946), "The Oxidation of Nitrogen in Combustion and Explosions", Acta Physicochim URSS, 21, pp. 577-628. 